\title{
Quantifying Natural Resources Using Field-Based Instruction and Hands-on Applications
}

\author{
Daniel R. Unger, David L. Kulhavy, I-Kuai Hung, \& Yanli Zhang \\ Arthur Temple College of Forestry and Agriculture \\ Stephen F. Austin State University \\ Box 6109, SFA Station \\ Nacogdoches, TX 75962, USA
}

Received: March 17, 2014 Accepted: March 27, 2014 Published: May 1, 2014

doi:10.5296/jse.v4i2.5309

URL: http://dx.doi.org/10.5296/jse.v4i2.5309

\begin{abstract}
Undergraduate students pursuing a Bachelor of Science in Forestry (BSF) degree at Stephen F. Austin State University (SFA) attend an intensive 6-week residential hands-on instruction in applied field methods. For students pursuing the BSF degree knowing the exact location, length, or area of a forestland is crucial to the understanding and proper management of any related natural resource. The intensive 6-week instruction includes teaching how to use the Global Positioning System (GPS) to accurately record the true spatial location of an earth's surface feature. After receiving hands-on instructions during the summer of 2013, students were taken to the field to collect real-world locations and area measurements. Upon returning from the field students were instructed how to assess the accuracy of their GPS collected waypoints by deriving the Root Mean Square Error (RMSE) comparing their GPS collected locations, derived perimeter and area assessments with the actual location, length and area respectively. Overall objective was to assess the effectiveness of GPS hands-on instruction methodology within a field-based setting. Since accurate quantitative data are crucial in any natural resource management plan, a student being able to accurately assess the real-world location and derived GPS perimeter and area measurements is essential.
\end{abstract}

Keywords: Hands-on, Applied, Instruction, Natural resources, Field-based 


\section{Introduction}

Undergraduate students pursuing a Bachelor of Science in Forestry (BSF) degree within the Arthur Temple College of Forestry and Agriculture (ATCOFA) at Stephen F. Austin State University (SFA), Nacogdoches, Texas, focus on the management of forests for wood products, wildlife habitat, recreational opportunities, and water quality. Students graduate with a clear understanding of how to meet goals defined by landowners and society while maintaining the ecological integrity of forests. Forest management artfully blends several scientific disciplines to achieve these goals. A forest manager must understand how plants and animals interact with their environment, possess a long-range view of a forest management plan, adapt to constantly changing economic conditions, and perceive the social interactions of people with the forest. Most importantly, a forest manager must recognize the forest as a dynamic entity that intimately links people, plants, and animals in a common community.

The mission of the BSF program within ATCOFA is to maintain excellence in teaching, research and outreach to enhance the health and vitality of the environment through sustainable management, conservation, and protection of our forests and natural resources. The college is dedicated to comprehensive undergraduate and graduate education, basic and applied research programs, and service. In the educational program, students receive classroom and field-based experiences to prepare them for their professional careers. Academic courses provide learning opportunities that encourage and inspire students to approach forest resource, social and environmental issues in a critical yet creative manner, identify and analyze key elements, and articulate ethical solutions. In the ATCOFA Strategic Plan, Initiative 4, the goal is to "Develop a learner-centered environment. Increase the use of teaching technologies, strategies, and active learning opportunities that enhance student engagement."

Focus groups have indicated that students who decide to attend ATCOFA do so because they have chosen to pursue a career path based on three main items of concern where they can: make a difference, work outdoors, and use high end technology. To facilitate their career objectives undergraduate coursework within ATCOFA focuses on hands-on instruction, field exercises, and real-world applications. All undergraduate students pursuing the BSF degree as part of their 130 credit requirement, who are majoring in forest management, wildlife, urban forestry, recreation or fire ecology, attend an off-campus residential 6-week hands-on intensive summer forestry field station. Students receive six credits for field station. The field station is currently after the junior year and will be transferred after the sophomore year starting summer 2014. A total of eight forestry classes are required prerequisites (Introduction to Forestry; Forest Wildlife Management; Forest Ecology; Wood Technology; Forest Measurements; Dendrology; Spatial Science; and Human Dimensions). All required prerequisites are three credit courses with a two hour lecture, three hour laboratory format except Human Dimensions which is a three hour lecture.

Field station is composed of intensive hands-on instruction in applied field methods where the students learn practical applications that a multidisciplinary society ready forester needs 
to master to solve problems, issues, and concerns resource managers' face on a daily basis. The 6-week hands-on instruction is broken down between field silviculture (two weeks), wildlife (one week), land measurements (one week), harvesting and saw milling (one week), and non-timber resources (one week). The timing and credits for field station are similar to other southern forestry schools accredited by the Society of American Foresters (Table 1). Although not unique to ATCOFA, as other forest schools have field stations identified in Table 1, the

Table 1. Field stations for academic institutions in the southeast United States with a forest major stratified by academic cycle, time of year and number of credit hours.

\begin{tabular}{rrrrr}
\hline Institution & $\begin{array}{r}\text { Field Station } \\
\text { (yes/no) }\end{array}$ & $\begin{array}{r}\text { Academic Cycle } \\
\text { (term) }\end{array}$ & $\begin{array}{r}\text { Time of Year } \\
\text { (season) }\end{array}$ & $\begin{array}{r}\text { Credit Hours } \\
\text { (semester) }\end{array}$ \\
\hline Alabama A\&M University & Yes & Soph./Jr. & Summer & 6 \\
Auburn University & Yes & Soph./Jr. & Summer & 12 \\
University of Florida & Yes & Soph./Jr. & Summer & 6 \\
University of Georgia & Yes & Soph./Jr. & Summer & 4 \\
University of Kentucky & Yes & Jr. & Spring & 14 \\
Louisiana State University & No & N//A & N//A & N//A \\
Louisiana Tech University & Yes & Jr./Sr. & Summer & 10 \\
Mississippi State University & Yes & Soph./Jr. & Summer & 9 \\
North Carolina State University & Yes & Soph./Jr. & Summer & 9 \\
Oklahoma State University & Yes & Soph./Jr. & Summer & 9 \\
Clemson University & Yes & Soph./Jr. & Summer & 8 \\
University of Tennessee & No & N//A & N//A & N//A \\
Stephen F. Austin State University & Yes & Jr./Sr. & Summer & 6 \\
Virginia Polytechnic Institute & No & N//A & N//A & N//A \\
Texas A\&M University & Yes & Soph./Jr. & Summer & 3 \\
\hline
\end{tabular}

overall objective was to assess the effectiveness of Global Positioning System (GPS) hands-on instruction methodology within an intensive field-based setting which has previously not been studied. Field station classes begin at 7:00 a.m. with field exercises until 5:00 p.m. followed by lecture and data analysis in the evening. Two faculty members rotate for each field station section for a total of 12 faculty members per summer. Since field station is a required component of each students degree program an institutional review board is not required by SFA to attend field station. 


\section{Macrothink}

\section{Piney Woods Conservation Center}

The forestry field station is located at the Piney Woods Conservation Center (PWCC), a residential conservation center located adjacent to Angelina National Forest on the shores of Sam Rayburn Reservoir approximately 15 miles south of Broaddus, Texas (Figure 1). Constructed in 1985 for Stephen F. Austin State University's College of Forestry, the facility is used year round by the university, private and professional groups.

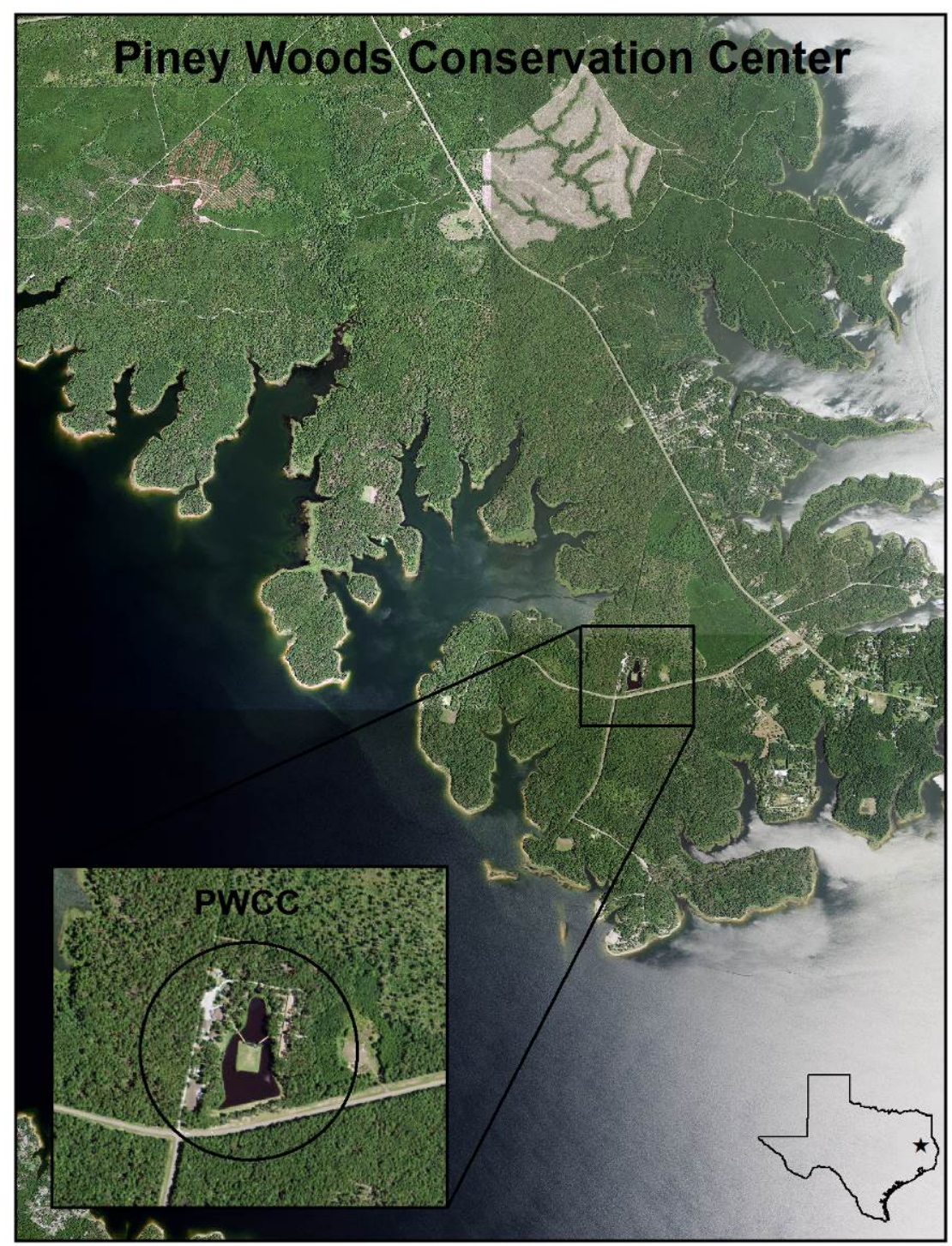

Figure 1. Location of the Piney Woods Conservation Center (PWCC) on the shores of Sam Rayburn Reservoir adjacent to the Angelina National Forest

PWCC can accommodate 128 people with sleeping quarters arranged in suites. For field station, two students share a room and four share a connecting bathroom. Two dining rooms are located at the lodge area, one seats 150 people; the other 70 . High quality meals are prepared and served from a modern kitchen. Four meeting rooms are available; two are 
centrally located within the dormitory buildings; one is located between the two dormitories; and one adjacent to the lodge. The meeting rooms can accommodate up to 150 people and are equipped with audio-visual equipment. Faculty members also occupy a room at PWCC within close proximity to the students creating a student-faculty centered learned environment.

Instructors utilize the meeting room located between the two dormitories as a classroom for the entirety of field station. A typical day starts in the classroom at 7:00 a.m. followed by hand-on instruction and data collection in the adjacent Angelina National Forest and private forest lands. After returning to PWCC at the end of each day, typically at 5:00 p.m., students utilize a meeting room centrally located within one of the dorms that is equipped as a computer lab to facilitate data analysis at the conclusion of each field day.

\section{WHY GPS?}

Spatial science, the study of spatial information describing the earth, its physical features and the built environment, incorporates geographic information systems (GIS), GPS, remote sensing, surveying, and cartography. The rapid advancement of spatial technology, now part of our daily lives, includes personal GPS navigation devices and smart phones, professional GIS software (for business, public safety, oil and gas industry, natural resources, logistics and transportation, etc.), and web-GIS.

For students pursuing the BSF degree within ATCOFA knowing how to use GPS to derive the exact location, length, or area of a forestland is crucial to the understanding and proper management of any related natural resource. GPS is a satellite based navigation system that allows the user to identify the exact location of an object on the surface of the earth 24 hours a day in all weather conditions (Thurston, Poiker, and Moore, 2003). Surface objects are collected and categorized by their surface feature and represent either a point (e.g. bear den, field plot, etc...), line (e.g. stream, river, road, etc...), or polygon (e.g. lake, forest management unit, etc...) (Clarke, 2003; Heit and Shortreid, 1991; Lang, 1998). With the collection of a surface feature location via GPS technology the exact location, calculated length of a linear feature, or calculated area of a polygon feature can be extracted.

During the land measurements portion of field station students are trained on a consumer-grade GPS unit, the Garmin eTrex Legend ${ }^{\circledR} \mathrm{HCx}$ (Garmin International Inc., Olathe, KS), representative of the type of GPS unit typically used by practicing natural resource managers within a forested environment. The use of a GPS unit in a forest environment presents many challenges (forest canopy blocks and degrades satellite signals and tree structure introduces multipath error) which the field stations students are introduced to in the central classroom before collecting data in the field. Sigrist, Coppin, and Hermy (1999) found that canopy has a definite effect on horizontal and vertical positional accuracy and the relation appeared to be exponential; a small increase in canopy density resulted in a substantial increase in error. Yoshimura and Hasegawa $(2003,2006)$ found that horizontal positional accuracy and precision errors were highest in areas of dense canopy cover and lowest in areas of sparse canopy cover. Wing, Eklund, and Kellogg (2005) found that consumer-grade GPS receivers were accurate within 5 meters under open sky, 7 meters under young canopy, and within 10 
meters under closed canopy in western Oregon. A study by Bolstad, Jenks, Berkin, Horne, and Reading (2005) confirmed those results with average errors of 6.5 and 7.1 meters under heavy forest canopy in Minnesota.

To prepare for field station, students are introduced to the Garmin eTrex Legend ${ }^{\circledR} \mathrm{HCx}$ (Garmin International Inc., Olathe, KS) in a required sophomore Spatial Science course. The rubric for the field station course, based on High Impact Teaching Practices for SFA, emphasizes field-based learning for juniors and seniors (Make An Impact @ SFA!, A Quality Enhancement Plan, http://www.sfasu.edu/iao/pdf/qep.pdf). To increase higher order thinking skills, the rubric includes Benchmark 1, Milestones 2 and 3, and Capstone. For the use of GPS, Benchmark 1 includes using the Garmin eTrex Legend ${ }^{\circledR} \mathrm{HCx}$ (Garmin International Inc., Olathe, KS) in GIS 224, a second year course in spatial science. Milestone 2 is reached in this course by one-on-one instruction on how to record real-world spatial locations. Milestone 3 is reached in field station and synthesized in the senior Capstone Management Plans course (Capstone rubric) where students construct maps using their collected spatial data. Integral to constructing the maps is a thorough understanding of how to use GPS to build point, line and polygon data.

\section{Interactive Field-Based Instruction Methodology}

Assessing the effectiveness of hands-on instruction within a field-based setting was completed at field station during summer 2013. Prior to beginning instruction 44 students were divided into 6 groups; 4 groups of 7 students per group and 2 groups of 8 students per group. Prior to going in the field to collect real-world point, line and polygon data via the Garmin eTrex Legend ${ }^{\circledR}$ HCx (Garmin International Inc., Olathe, KS), students were instructed in the central classroom how to enable their GPS unit to ensure that their GPS unit will collect data with real time correction via the Satellite Based Augmentation System (SBAS) (Figure 2) (Milestone 2). SBAS is a collection of satellite systems that provide real time corrections data to GPS receivers to increase the accuracy of waypoints. The system in use in North America is the Wide Area Augmentation System (WAAS) consisting of 38 ground reference stations in the U.S., Canada and Mexico. The stations monitor GPS satellite data and transfer that data to three master stations which then upload correction messages (error) to multiple geosynchronous satellites. 


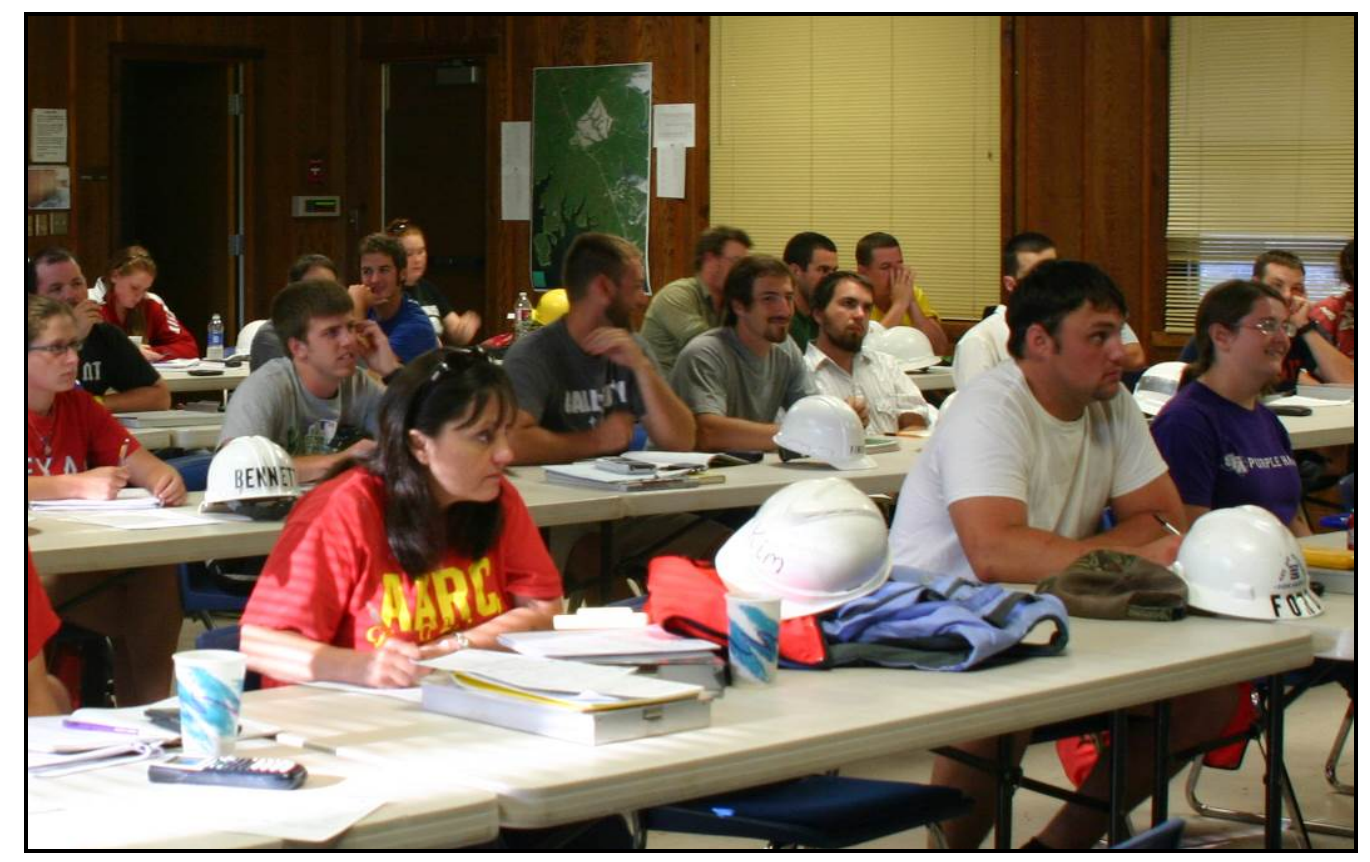

Figure 2. Students are instructed in the central classroom how to enable their Garmin eTrex Legend ${ }^{\circledR}$ HCx GPS unit to ensure Satellite Based Augmentation System data collection for their point, line and polygon data

These satellites in turn distribute the correction message to GPS receivers that can apply the real time corrections in the field to increase waypoint accuracy thus increasing the accuracy of any derived real-world unit (Arnold and Zandbergen, 2011; Federal Aviation Administration [FAA], 2010). Federal Aviation Administration specifications require that WAAS will provide 7.6 meter horizontal accuracy, a sizable improvement on the 10-15 meter accuracy that is usually specified for most consumer-grade GPS units gathering data autonomously (FAA, 2008).

Once the GPS units were configured to be WAAS enabled, the students were then taken to the island in the central portion of PWCC to receive one-on-one faculty instruction on how to collect a waypoint (Figure 3). A waypoint captures the GPS derived real-world coordinates representing the actual location of each GPS unit. Students were also instructed how to collect waypoint location data in the Universal Transverse Mercator (UTM) coordinate system, the typical coordinate system required by most natural resource based entities. The island is the preferred place within PWCC for initial hands-on GPS instruction outside as it provides a full view of the sky thereby minimizing multipath error making the initial introduction to students on how to use a GPS more effective. Following waypoint data collection, students received one-on-one faculty instruction on how to use their GPS unit to interactively quantify area. Students were instructed how to identify a starting point for a GPS recorded track and were then instructed to walk the perimeter of the island while receiving verbal instruction on how to store and save the island perimeter as a track resulting in an on-screen assessment of area in the 


\section{Macrothink}

Journal of Studies in Education

ISSN 2162-6952

2014, Vol. 4, No. 2

users preferred unit of measure (Milestone 2). This is the pre-test measure prior to the field project.

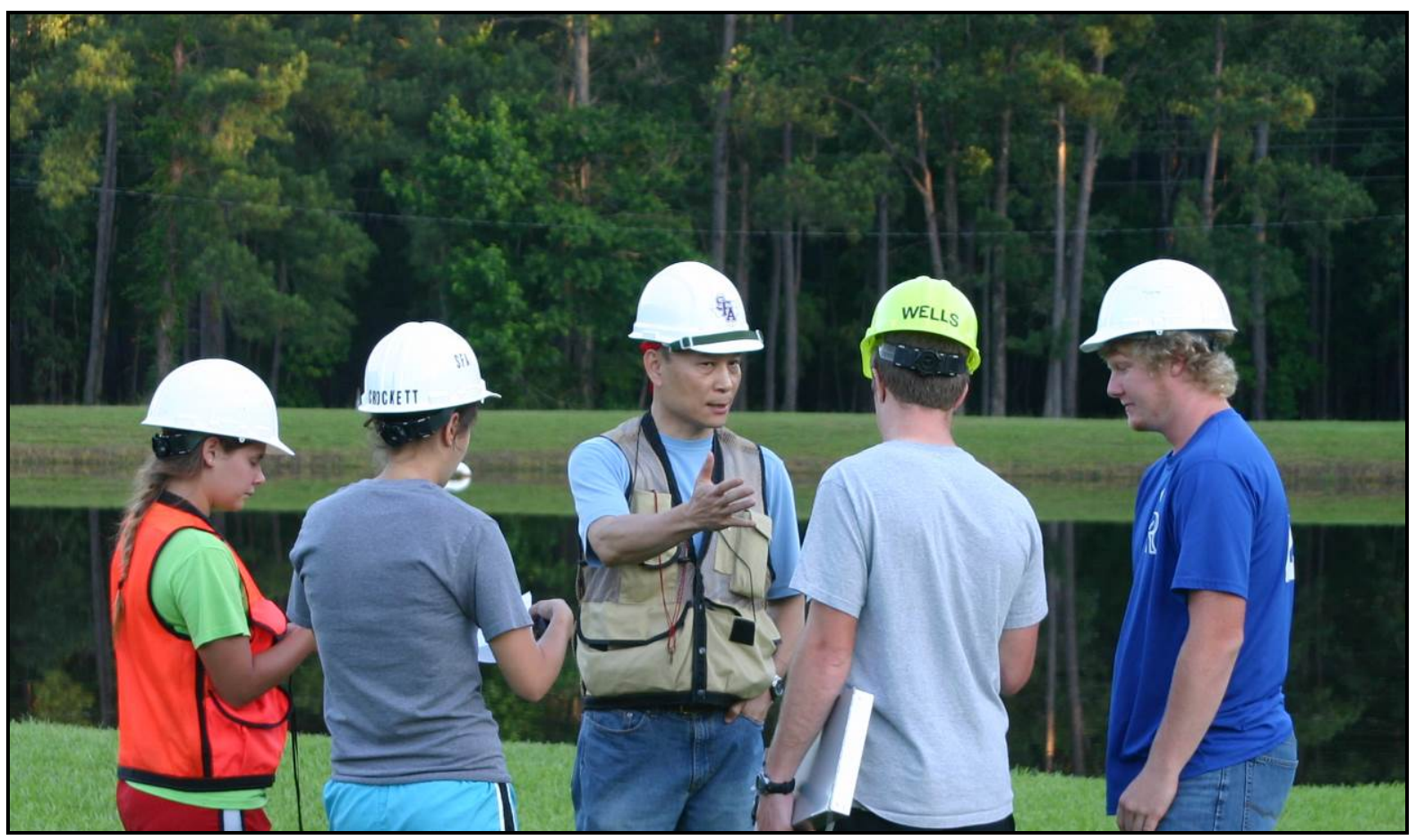

Figure 3. Students receiving one-on-one faculty instruction on how to collect a waypoint and calculate area on the island within the confines of the Piney Woods Conservation Center

Once the initial hands-on instruction on the island was been completed, students were taken to the field to collect waypoints and calculate the length and area of faculty chosen waypoint and area locations respectively (Figure 4). The students navigated to each identified waypoint and area in groups ranging from 7 to 8 students per group. In the field the students collected data independently to increase confidence and to validate their knowledge as Milestone 3 in the rubric. Faculty members travelled from group to group to reinforce waypoint collection and provide further instruction as needed.

\section{Interactive GIS Lab Data Analysis}

After all waypoint and area locations in the field were recorded, the students returned to PWCC and used the meeting room that is transformed and equipped as a computer lab for data analysis. The students then received one-on-one faculty instruction on how to transfer the collected waypoints and tracks within the Garmin eTrex Legend ${ }^{\circ} \mathrm{HCx}$ (Garmin International Inc., Olathe, KS) to ArcMap 10.1 (Environmental Systems Research Institute, Redlands, CA) using DNRGPS (Department of Natural Resources, State of Minnesota) software to communicate between the Garmin eTrex Legend ${ }^{\circledR}$ HCx (Garmin International Inc., Olathe, KS) and a desktop PC (Figure 5). ArcMap 10.1 (Environmental Systems Research Institute, Redlands, CA) was utilized to produce high quality map products 


\section{Macrothink}

portraying the spatial location of each collected waypoint, length and area assessment for inclusion in their daily report.

For students pursuing the BSF degree within ATCOFA knowing how to record an actual location and calculate an accurate perimeter and area of a polygon is crucial to the understanding and proper management of natural resources. To achieve that objective, the six students groups were instructed within the computer lab how to assess the accuracy of their GPS collected waypoints by deriving the Root Mean Square Error (RMSE) between their GPS collected locations and each waypoints real-world location (Table 2) (Milestone 3). The interactive GIS lab was used to reinforce one-on-one faculty interaction to increase a student's retention of the presented material. RMSE was utilized so the students could evaluate and quantify the effectiveness of their ability to acquire accurate real-world coordinates. An RMSE analysis was also used to evaluate and validate the effectiveness of the one-on-one faculty instruction demonstrating how to acquire accurate perimeter and area measurements of polygons within the Angelina National Forest (Table 3a and 3b).

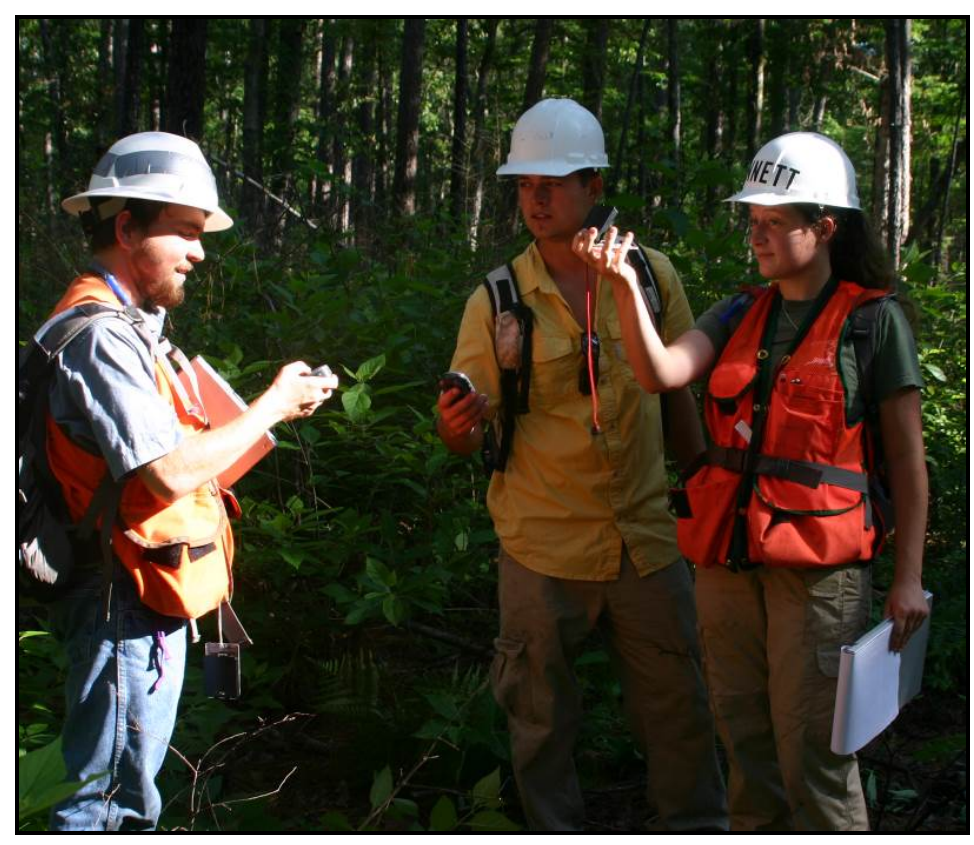

Figure 4. Students collecting waypoints and track logs to calculate the length and area of faculty chosen waypoint and area locations within the Angelina National Forest 


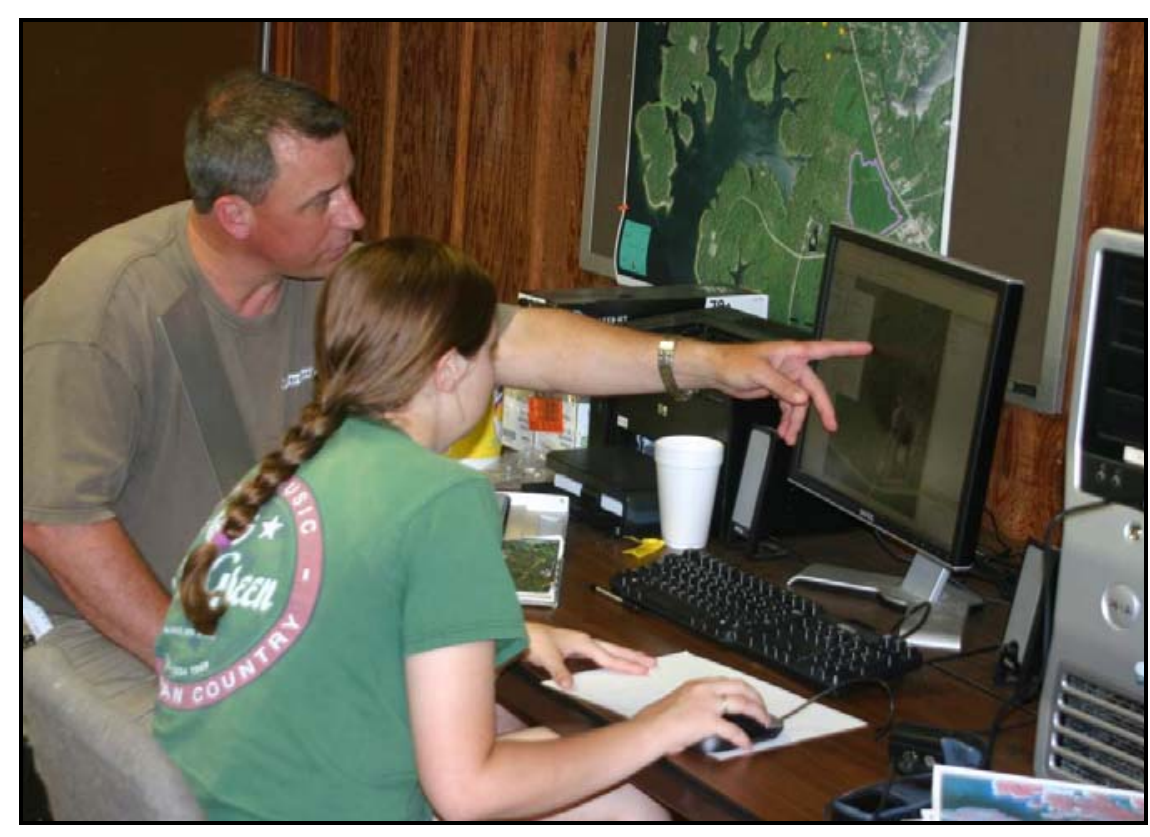

Figure 5. Students receiving one-on-one faculty instruction on how to transfer the collected waypoints and tracks within the Garmin eTrex Legend® ${ }^{\circledR} \mathrm{HCx}$ to ArcMap 10.1 using DNRGPS software to communicate between the Garmin eTrex Legend ${ }^{\circledR}$ HCx and ArcMap 10.1 after returning from the field

\section{Individual GPS Exam}

After gaining confidence within a group setting on how to effectively use a GPS in the field the students were then tested individually via a GPS hands-on exam assessing their ability to accurately record waypoint locations and calculate area (Table 4). Waypoints identified within the confines of PWCC were chosen to assess the accuracy of each student's ability to accurately collect real-world spatial location data. The actual coordinates of each waypoint were derived by the faculty through on-screen digitizing and recording the UTM coordinates of each waypoint with industry standard GIS software ArcMap 10.1 (Environmental Systems Research Institute, Redlands, CA) using high spatial resolution multispectral digital imagery at 1.0 meter resolution of PWCC as an image backdrop. Area locations within the Angelina National Forest were chosen to assess the accuracy of each student's ability to accurately collect real-world length and area data within a real-world forested setting. The actual perimeter and area of each identified area location were derived by the faculty through on-screen digitizing based on the high spatial resolution imagery representing PWCC. 


\section{Ml Macrothink}

Journal of Studies in Education

ISSN 2162-6952

2014, Vol. 4, No. 2

Table 2. Accuracy assessment of GPS collected waypoints by deriving the Root Mean Square Error between student collected GPS locations and the faculty provided real-world locations at 6 different locations

\begin{tabular}{|c|c|c|c|c|c|c|}
\hline Group & $\begin{array}{r}\text { GPS } \\
\text { Easting } \\
\text { (meters) }\end{array}$ & $\begin{array}{r}\text { GPS } \\
\text { Northing } \\
\text { (meters) }\end{array}$ & $\begin{array}{r}\text { Actual } \\
\text { Easting } \\
\text { (meters) }\end{array}$ & $\begin{array}{r}\text { Actual } \\
\text { Northing } \\
\text { (meters) }\end{array}$ & $\begin{array}{r}\text { Euclidian } \\
\text { Distance } \\
\text { (meters) }\end{array}$ & $\begin{array}{r}\text { Squared } \\
\text { Error } \\
\text { (meters) }\end{array}$ \\
\hline 1 & 394248.33 & 3444237.13 & 394245.13 & 3444234.15 & 4.37 & 19.12 \\
\hline 2 & 394298.26 & 3444011.40 & 394297.46 & 3444015.20 & 3.88 & 15.08 \\
\hline 3 & 394307.09 & 3443993.85 & 394310.08 & 3443995.65 & 3.49 & 12.18 \\
\hline 4 & 394340.25 & 3443928.97 & 394341.35 & 3443924.87 & 4.24 & 18.02 \\
\hline 5 & 394394.74 & 3443869.21 & 394390.64 & 3443871.31 & 4.61 & 21.22 \\
\hline \multirow[t]{3}{*}{6} & 394248.77 & 3443830.22 & 394247.97 & 3443838.72 & 8.54 & 72.89 \\
\hline & & & & Mean & 4.86 & 26.42 \\
\hline & & & & & & 5.14 \\
\hline
\end{tabular}

\section{Results}

Hands-on teaching effectiveness within a field-based setting was evaluated by assessing the accuracy of GPS collected waypoints be calculating the RMSE between student collected GPS locations and faculty provided real-world locations at 6 different sites. Student collected waypoint locations, when collected in a group setting, resulted in an RMSE of 5.14 meters (SD, 26.42 meters). Student calculated perimeter and area measurements, when collected in a group setting, resulted in a perimeter RMSE of 10.78 feet (SD, 116.17 feet) and an area RMSE of 0.14 acres (SD, 0.02 acres). When students were tested individually via a hands-on GPS exam the accuracy of their individual measurements decreased relative to their group participation scores. When participating in a group setting 91 percent of group scores were $\geq$ 90 percent and 9 percent were $\geq 80$ percent and $<90$ percent. When tested individually 77 percent of individual GPS exam scores were $\geq 90$ percent and 16 percent were $\geq 80$ percent and $<90$ percent. Seven percent of individual GPS exam scores were $<80$ percent overall with 0.05 percent of individual student scores $<70$ percent. These results demonstrate that the field-based instruction and hands-on applications employed by ATCOFA faculty can lead to highly accurate derived real-world GPS derived perimeter and area measurements by students as demonstrated with high group participation lab scores and high individual exam scores. 
Table 3a-b. Validating the effectiveness of one-on-one faculty instruction on how to acquire accurate perimeter and area measurements of polygons within the Angelina National Forest by comparing the Root Mean Square Error between students collected perimeter and area measurements with faculty provided real-world perimeter and area measurements.

a)

\begin{tabular}{rrrrrrr}
\hline Group & $\begin{array}{c}\text { Perimeter } \\
\text { Actual } \\
\text { (feet) }\end{array}$ & $\begin{array}{c}\text { Area } \\
\text { Actual } \\
\text { (acres) }\end{array}$ & $\begin{array}{c}\text { Perimeter } \\
\text { eTrex HCx } \\
\text { (feet) }\end{array}$ & $\begin{array}{c}\text { Area } \\
\text { eTrex HCx } \\
\text { (acres) }\end{array}$ & $\begin{array}{c}\text { Perimeter } \\
\text { Difference } \\
\text { (feet) }\end{array}$ & $\begin{array}{c}\text { Area } \\
\text { Difference } \\
\text { (acres) }\end{array}$ \\
\hline 1 & 1027 & 1.6 & 1019 & 1.5 & 8.00 & 0.10 \\
2 & 1027 & 1.6 & 1015 & 1.6 & 12.00 & 0.00 \\
3 & 1027 & 1.6 & 1042 & 1.3 & -15.00 & 0.30 \\
4 & 1027 & 1.6 & 1029 & 1.5 & -2.00 & 0.10 \\
5 & 1027 & 1.6 & 1011 & 1.7 & 16.00 & -0.10 \\
6 & 1027 & 1.6 & 1025 & 1.6 & 2.00 & 0.00 \\
\hline & & & & Mean & $\mathbf{3 . 5 0}$ & $\mathbf{0 . 0 7}$ \\
& & & & SD & $\mathbf{1 1 . 1 7}$ & $\mathbf{0 . 1 4}$ \\
\hline
\end{tabular}

b)

\begin{tabular}{rrrrr}
\hline Group & $\begin{array}{c}\text { Absolute Perimeter } \\
\text { Difference } \\
\text { (feet) }\end{array}$ & $\begin{array}{c}\text { Absolute Area } \\
\text { Difference } \\
\text { (acres) }\end{array}$ & $\begin{array}{c}\text { Squared Perimeter } \\
\text { Difference } \\
\text { (feet) }\end{array}$ & $\begin{array}{c}\text { Squared Area } \\
\text { Difference } \\
\text { (acres) }\end{array}$ \\
\hline 1 & 8.00 & 0.10 & 64.00 & 0.01 \\
2 & 12.00 & 0.00 & 144.00 & 0.00 \\
3 & 15.00 & 0.30 & 225.00 & 0.09 \\
4 & 2.00 & 0.10 & 4.00 & 0.01 \\
5 & 16.00 & 0.10 & 256.00 & 0.01 \\
6 & 2.00 & 0.00 & 4.00 & 0.00 \\
\hline Mean & $\mathbf{9 . 1 7}$ & $\mathbf{0 . 1 0}$ & 116.17 & 0.02 \\
SD & $\mathbf{6 . 2 1}$ & $\mathbf{0 . 1 1}$ & $\mathbf{1 0 . 7 8}$ & $\mathbf{0 . 1 4}$ \\
\hline & Absolute Error & Absolute Error & RMSE & RMSE \\
\hline
\end{tabular}

Table 4. Questions correct by eTrex group participation lab and eTrex individual hands-on final examination

\begin{tabular}{ccccc}
\hline $\begin{array}{c}\text { Questions } \\
\text { Correct } \\
\text { (percent) }\end{array}$ & $\begin{array}{c}\text { eTrex Lab } \\
\text { Group Participation } \\
\text { (number of students) }\end{array}$ & $\begin{array}{c}c \\
\text { (percent of class) }\end{array}$ & $\begin{array}{c}\text { eTrex Final } \\
\text { Individual Exam } \\
\text { (number of students) }\end{array}$ & (percent of class) \\
\hline$\geq 90$ & 40 & 0.91 & 34 & 0.77 \\
$\geq 80$ & 4 & 0.09 & 7 & 0.16 \\
$\geq 70$ & 0 & 0.00 & 1 & 0.02 \\
$\geq 60$ & 0 & 0.00 & 2 & 0.05 \\
\hline
\end{tabular}




\section{Student Learning Outcomes}

Students who attend ATCOFA do so because they have chosen to pursue a career path based on three main items of concern: make a difference, work outdoors, and use high end technology to solve problems, issues, and concerns resource managers face on a daily basis. To achieve that objective undergraduate coursework within ATCOFA focuses on hands-on instruction, field exercises, and real-world applications within the field station portion of their curriculum. Developed from a college wide curriculum revision for forest instruction, a word cloud analysis of this article demonstrates that the student centered hands-on real-world application objectives of faculty within ATCOFA are being effectively applied within the land measurements portion of field station (Figure 6).

Within the land measurement portion of field station students learned via one-on-one faculty instruction how to use a GPS unit to collect waypoints and assess their accuracy relative to their spatial location and any derived perimeter and area calculations. Students learned how to accurately use GPS to calculate real-world measurements. One hundred percent of students, when working in a group setting, scored $\geq 80$ percent on a group participation lab. Ninety-three percent of students scored $\geq 80$ percent when tested individually on a hands-on GPS exam. The high lab and exam scores of students attending field station in the summer of 2013 validate the teaching effectiveness of ATCOFA faculty in quantifying natural resources using field-based instruction and hands-on applications. Since accurate quantitative data are crucial in any natural resource management plan, a student being able to accurately assess real-world location and derived GPS perimeter and area measurements is essential. Instructors of students pursuing a natural resource based degree at other institutions can learn from the field-based instruction and hands-on applications employed by ATCOFA that minimal instruction time can lead to highly accurate real-world GPS derived perimeter and area measurements.

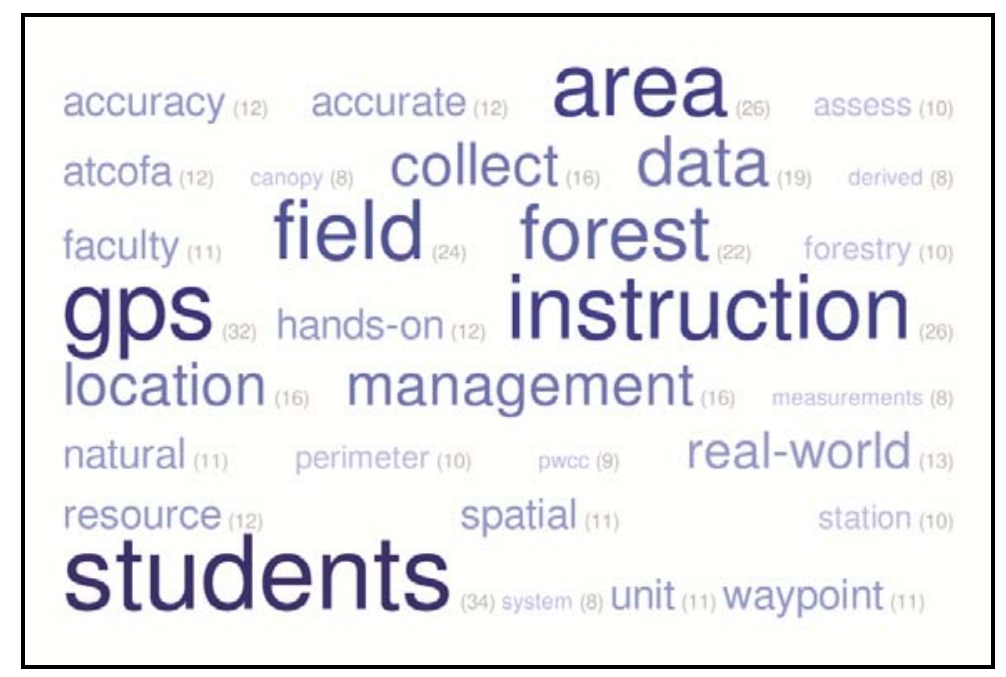

Figure 6. Word cloud analysis of this article demonstrating student centered hands-on real-world applications are being effectively applied within the land measurements portion of field station. 


\section{Macrothink}

\section{References}

Arnold, L., \& Zandbergen, P. (2011). Positional accuracy of the Wide Area Augmentation System in consumer-grade GPS units. Computers \& Geoscience, 37, 883-892. http://dx.doi.org/ 10.1016/j.cageo.2010.12.011

Bolstad, P., Jenks, A., Berkin, J., Horne, K., \& Reading, W. H. (2005). A comparison of autonomous, WAAS, real-time, and post-processed global positioning systems (GPS) accuracies in northern forests. Northern Journal of Applied Forestry, 22, 5-11.

Clarke, K. (2003). Getting started with geographic information systems. Upper Saddle River, New Jersey: Prentice Hall.

FAA. (2008). Wide-area augmentation system performance analysis report. Federal Aviation Administration, William J. Hughes Technical Center, NSTB/WAAS T\&E Team Report No. 24.

FAA. (2010). WAAS: Quick facts, 2010. Federal Aviation Administration. Retrieved from http://www.faa.gov/about/office_org/headquarters_offices/ato/service_units/techops/navservi ces/gnss/waas/

Heit, L., \& Shortreid, A. (1991). GIS applications in natural resources. Loveland, Colorado: J. L. Printing.

Lang, L. (1998). Managing natural resources with GIS. Redlands, California: ESRI.

Sigrist, P., Coppin, M., \& Hermy, M. (1999). Impact of forest canopy on quality and accuracy of GPS measurements. International Journal of Remote Sensing, 20, 3595-3610. http://dx.doi.org/10.1080/014311699211228

Thurston, J., Poiker, T., \& Moore, J. (2003). Integrated spatial technologies. New Jersey: John Wiley \& Sons.

Wing, M., Eklund, A., \& Kellogg, L. (2005). Consumer-grade global positioning system (GPS) accuracy and reliability. Journal of Forestry, 103, 169-173.

Yoshimura, T., \& Hasegawa, H. (2003). Comparing the precision and accuracy of GPS positioning in forested areas. Journal of Forest Research, 8, 147-152. http://dx.doi.org/10.1007/s10310-002-0020-0

Yoshimura, T., \& Hasegawa, H. (2006). High-end GPS vs. low-end GPS: comparing GPS positioning accuracy in the forest environment. In UFRO Precision Forestry Symposium, Stellenbosch, South Africa, p. 429-436. 